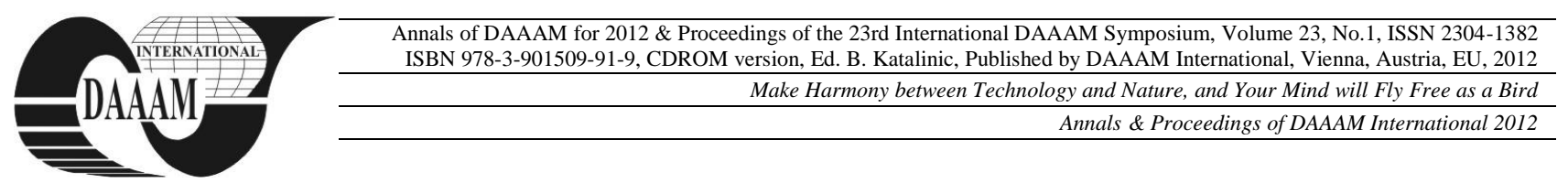

\title{
WEATHER RISK MANAGEMENT IN ENERGY SECTOR
}

\author{
STULEC, I[vana]; BAKOVIC, T[omislav] \& HRUSKA, D[omagoj]
}

\begin{abstract}
The paper examines the problem of adverse weather effects on energy sector, outlines possible weather risk management strategies and presents weather derivatives as currently most effective instrument of weather protection. Weather effects both energy consumption and production, and poses significant source of risk especially when considering energy production from renewable sources. The paper presents possible applications of weather derivatives in energy sector, both in a case of energy consumption (natural gas sales) and in the case of energy production (wind power plant production). Examples are of hypothetical nature, but entities interested in weather risk management can perform necessary analysis following the proposed analogy.
\end{abstract}

Keywords: weather risk, weather risk management, weather derivatives, energy sector

\section{INTRODUCTION}

It has long been argued that weather directly or indirectly influences production and consumption in almost every economic activity at all temporal and geographical scales. Through history many unexpected expenses and foregone revenues have been blamed on weather. Only recently weather got the much needed attention, in both scientific literature and business, which can be attributed to ever more obvious effects of climate change and omnipresent economic crisis which forced companies to strengthen their expenses control.

Research shows that $80 \%$ of world economy is, directly or indirectly, sensitive to weather [1]. Reference [2] conducted "a first comprehensive empirical analysis of the sensitivity of the U.S. economy as a whole to weather variability" and found that every sector is statistically significant to at least one measure of weather variability. Reference [3] assessed impacts of weather on selected tertiary activities and found that relationships betweens weather and production are much less straightforward than those between weather and energy use. According to the study on weather sensitivity conducted among 68 countries worldwide, $34 \%$ of Croatian economy is directly influenced by weather [4]. Survey conducted among large Croatian companies [5] found that following sectors are perceived to be most weather sensitive: agriculture, construction, trade, tourism and energy. Further on, temperature and rain are perceived to have highest impact on business among weather variables.

The paper gives an overview of literature on weather risk and weather risk management strategies, with special emphasis being put on energy sector. The purpose of the paper is to popularize the subject of weather risk management among scientific and general public and to promote weather derivatives as the most effective instrument of protection against weather risk.

The paper is organized as follows. After introduction to the subject of the paper, weather risk is defined, specificities of weather risk which urged for development of new risk management solution are addresses and literature on weather risk in energy sector is reviewed. Third part of the paper presents weather risk management strategies and their possible application in energy sector. In the fourth part of the paper, weather derivatives are presented as currently most effective weather risk management tool and their potential apalication in energy sector is corroborated with two hypothetical examples. Final part of the paper gives concluding remarks.

\section{WEATHER RISK IN ENERGY SECTOR}

Before discussing weather risk in energy sector, definition of weather risk should be addressed. In order to define weather risk, it is necessary to point out the differences between terms catastrophic and noncatastrophic weather. Catastrophic weather events include floods, hurricanes, tornadoes, windstorms etc. They have a low probability of occurrence and if they occur they cause massive financial damages. On the other hand, non-catastrophic weather relates to the minor deviations from "normal" or usual weather, such as wormer than usual winter or cooler than usual summer. In addition to temperature variations, non-catastrophic weather includes deviations from normal rainfall and snowfall, wind speed, number of sunshine hours, days in which frost or fog were recorded etc. Non-catastrophic weather can be summed into those weather events that affect company's income and/or cost but do not threaten lives and property [6]. Having explained the basic terms, the definition of weather risk can be given. Weather risk is defined as the uncertainty in future cash flows as a result of non-catastrophic weather [7].

As a source of risk, weather is specific because it primarily affects the quantity of production and demand for a certain good, and not the price at which the good is being sold [8]. In other words, the weather poses a risk of adverse quantity change (volumetric risk) and not price change (price risk). As an example of unfavourable weather impact on demand, the literature often mentions the reduced consumption of heating energy (natural gas, heating oil) during the unusually warm winters. Using the same analogy, it can be concluded that cooler 
summers result in lower consumption of electric energy used for air-coinditioning. In addition to demand, weather also affects the supply, i.e. the quantity produced. The construction industry, for example, is largely dependent on weather in a way that low temperatures and heavy rainfall can cause delays and interruptions in the construction work and, consequently, the payment of penalties. Furtheron, hydroelectric plants and wind power plants are haivily reliant on rainfall and wind speed, respectively. Weather conditions also significantly affect the quantity and quality of yields in agriculture. These are just some of many industries whose operating results are affected by weather. Similary, weather risk can be found in almost every economic activity. Furthermore, weather risk is unique because weather is not a physical good. However, even though the weather cannot be physically exchanged, it is possible to exchange i.e. trade financial exposure to weather, through the use of appropriate financial derivatives. In addition, weather risk is highly geographically localized, meaning that weather varies significantly even when it comes to the small spatial distances.

Weather has long been recognized as a source of risk in energy sector since it affects both energy consumption in a short run and energy production in a long run. When talking of energy consumption, temperature proves to have the highest affect on consumption of natural gas in the winter [9] and consumption of electricity mainly in the summer $[10,11,12])$. Regarding energy production, hydroelectric plants are highly dependent on rainfall [13] and wind power plants on wind speed [14].

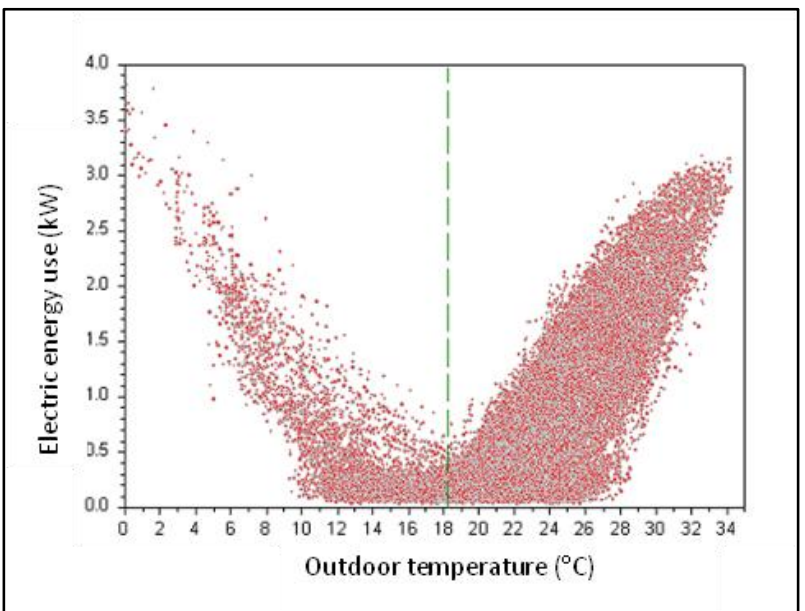

Fig. 1. Correlation plot of outdoor temperature $\left({ }^{\circ} \mathrm{C}\right)$ and electric energy use $(\mathrm{kW})$.

\begin{tabular}{|c|c|c|c|c|c|}
\hline Day & $\begin{array}{c}\text { Min. } \\
\text { temp. } \\
\left({ }^{\circ} \mathrm{C}\right)\end{array}$ & $\begin{array}{c}\text { Max. } \\
\text { temp. }\left({ }^{\circ} \mathrm{C}\right)\end{array}$ & $\begin{array}{c}\text { Aver. } \\
\text { temp. }\left({ }^{\circ} \mathrm{C}\right)\end{array}$ & HDD & $\begin{array}{c}\text { Cum. } \\
\text { HDD }\end{array}$ \\
\hline 1 & 3 & 10 & 6.5 & 11.5 & 11.5 \\
\hline 2 & 2 & 9 & 5.5 & 12.5 & 24.0 \\
\hline 3 & 4 & 8 & 6.0 & 12.0 & 36.0 \\
\hline 4 & 1 & 5 & 3.0 & 15.0 & 51.0 \\
\hline 5 & 0 & 4 & 2.0 & 16.0 & 67.0 \\
\hline 6 & 6 & 12 & 9.0 & 9.0 & 76.0 \\
\hline 7 & -1 & 4 & 1.5 & 16.5 & 92.5 \\
\hline
\end{tabular}

Tab. 1. Computation of a weekly cumulative HDD index $\left({ }^{\circ} \mathrm{C}\right)$

Fig. 1. presents a typical relationship between residential electric energy consumption and outdoor temperature. It can be seen that temperature-energy relationship is nonlinear and has two branches. Temperature of $18^{\circ} \mathrm{C}$ acts as a threshold level since at that temperature the energy consumption is minimal, at lower temperatures there is a negative relationship and at higher temperatures thare is a positive relationship between outdoor temperature and energy use. For that reason, the concept of degree days (DD) had been introduced which is defined as positive difference between mean daily temperature and base temperature. Two DD indices are used: heating degree days (HDD) index which measures severity of winter and cooling degree days (CDD) index which measures severity of summer. For the calculations of the two indices, equations (1) and (2) are used:

$$
\begin{aligned}
& \mathrm{HDD}=\max \left(\mathrm{T}_{\text {base }}-\mathrm{T}, 0\right) \\
& \mathrm{CDD}=\max \left(\mathrm{T}-\mathrm{T}_{\text {base }}, 0\right)
\end{aligned}
$$

$\mathrm{T}$ is average daily temperature and Tbase is base temperature. Average daily temperature is computed as an average of daily minimum and maximum temperature. The base temperature is set at the temperature for which consumption is minimal, which is in this case $18^{\circ} \mathrm{C}$, a pleasant room temperature that requires no space conditioning. CDD index is commonly used for summer periods and HDD for winter periods. HDD is also used for modelling natural gas and heating energy consumption during winters. The main advantage of using derived indices such as CDD and HDD, as predictors of energy consumption, rather than pure average temperature, is that they entail only those temperature levels that induce consumption.

When analysing weather sensitivity in some longer period such as a week, month, quarter or a year, accumulated weather indices are used. Such accumulated indices are computed by simple summation of daily values of weather indices. Tab. 1. shows how a weekly cumulative HDD index is computed. Cumulative HDD index for the observed 7-day perid is 92.5 points.

In a case of energy production in wind power plants, weather risk occurs in the form of too low or too high wind speeds. Adequate wind speeds depend on the type of a wind turbine, and mainly range between 3 and 15 $\mathrm{m} / \mathrm{s}$. Fig. 2. shows a relationship between wind speed $(\mathrm{m} / \mathrm{s})$ and output power $(\mathrm{kW})$ for Vestas V90 wind turbine. Wind speed of $3.5 \mathrm{~m} / \mathrm{s}$ acts as a cut-in speed, a minimum wind speed required for work of a wind turbine. Wind speed of $15 \mathrm{~m} / \mathrm{s}$ acts as a rated wind speed, a wind speed at which turbine works at its full strength (which is in the case of turbine V90 a power of 3,000 kW as it can be seen from the Fig. 2.). Above this wind speed level the production of electric energy will not increase along with the wind speed. Wind speed of $25 \mathrm{~m} / \mathrm{s}$ acts as a cut-off speed, a level at which safety limit is exceeded (occurs during hurricans and storms) and turbine switches off automatically. The main risk for wind power plants are unexpected wind speed variations that cause lower than planned production outputs and consequently lower than planned incomes.

Using the same analogy as with weather risk posed by temperature, it is better to compute a derived wind 
index which entails only those wind speed levels that induce electric energy production, e.g. cumulated wind speed index (CWSI) that summarizes daily wind speeds over a covered time span, taking into consideration the start and the full power thresholds of wind turbines. In the case of a Vestas V90 turbine the thresholds are wind speeds of 3.5 (4.0 integer) and $15 \mathrm{~m} / \mathrm{s}$ respectively. Tab. 2 . shows how weekly CWSI $(4 ; 15)$ is computed. The CWSI for the observed 7 -day period is 63 points.

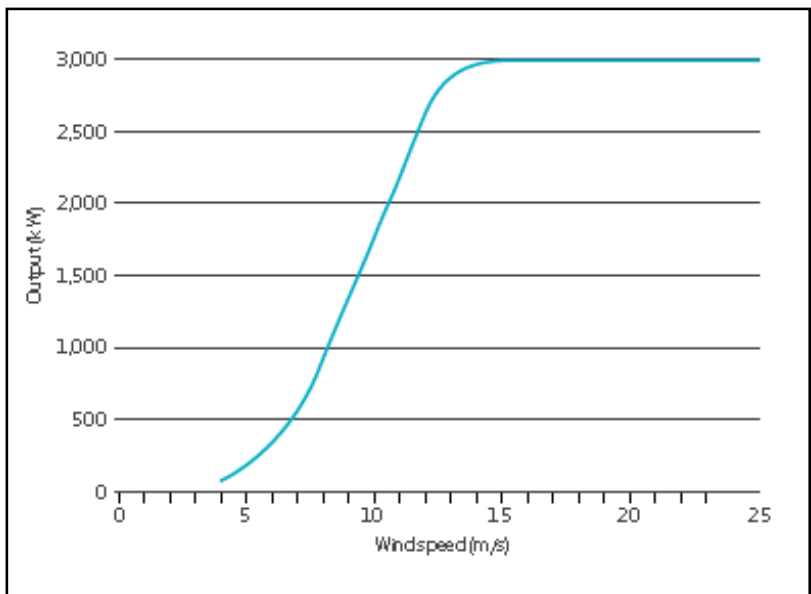

Fig. 2. Power curve for V90 wind turbine

\begin{tabular}{|c|c|c|}
\hline Day & $\begin{array}{c}\text { Average daily wind } \\
\text { speed }(\mathrm{m} / \mathrm{s})\end{array}$ & CWSI (4; 15) \\
\hline 1 & 2 & 0 \\
\hline 2 & 4 & 4 \\
\hline 3 & 9 & 13 \\
\hline 4 & 6 & 33 \\
\hline 5 & 14 & 48 \\
\hline 6 & 18 & 63 \\
\hline 7 & 16 & \\
\hline
\end{tabular}

Tab. 2. Computation of a weekly CWSI $(4 ; 15)$

\section{WEATHER RISK MANAGEMENT}

In the past, many companies had completely avoided weather risk management or were simply trying to cope with the consequences of adverse weather as good as they could. Today, principles of weather risk management are needed as never before. Available risk management strategies can be devided into four basic groups, regardless of the risk type [15]. They are, in order of their effectiveness: (1) avoidance, (2) acceptance, (3) reduction and (4) transfer.

(1) Strategy of avoidance entails avoiding of all activities associated with risk. When speaking of weather risk, the company using this strategy would simply decide not to sell or produce their products and services in areas with historically unfavourable weather. In the context of wind energy production, one would simply locate wind power plant in geographical area with historically favourable wind speeds. Even though this is a sound decision, weather risk is still not completely avoided since wind speeds, as all weather variables, deviate from historical averages and consequentlly so does the energy production. Disadvantage of this strategy is even more pronounced when one is considering natural gas consumption; one can decide to sell natural gas only to areas with historically cold winters but still is subjected to weather risk since temperature tend to deviate from historical average.

(2) Strategy of acceptance entails acceptance of losses incurred as a result of adverse events. Mainly is about small risk that is hard to cover with insurance because premium cost would most likely exceed overall risk exposure. Weather risk is often managed in this way - the company simply takes into consideration possible risk when projecting volume of production and sales.

(3) Strategy of reduction entails reduction of actual risk exposure and mitigation of consequences of adverse weather events. The most common examples of weather risk reduction are geographic and product diversification. Companies heavily reliant on one type of weather can reduce their weather dependency by diversifying their present product line or by expanding their operations onto new geographical areas. Product diversification can be defined as product line expansion with those products and services of which sale is enhanced by different weather events. Geographical diversification entails establishing new premises in geographically distant locations with opposite weather characteristics, i.e. negatively correlated meteorological elements, so as to reduce overall effect of weather on company profits. For companies that have diversified their sales across regions, products and services, one can say that are protected by the nature of their business i.e. that are naturally hedged. An example of natural hedge achieved by product diversification is an energy company that owns both hydroelectric plant and solar power plant. Such diversification is effective because rain is negatively correlated with sunshine hours. Natural hedge is much more difficult to achieve through geographical diversification because the feature of negative correlation between meteorological elements in different locations is often not the case in the market size of a single country or even a region. The advantage of natural hedge is that company does not need to pay for it. However, the disadvantage is that weather risk is not eliminated, merely reduced. Moreover, company continues to bear all the consequences of adverse weather because risk is not being transferred onto the party better suited to manage it. Nevertheless, geographical and product diversification is ofted cited as basic weather risk management strategies that companies apply worldwide [16].

(4) The strategy of transfer entails the risk transferring process to another party and as such represents the most successful i.e. effective strategy of risk management. A classic example of risk transfer is an insurance contract. Companies exposed to weather risk can also be protected by transferring the risk through contractual contingencies and commodity futures, while even more effective protection can be provided by weather derivatives (which will be addressed later in the paper). Commodity futeres have been recognised as valuable price risk management tool by Croatian energy sector $[17,18]$. However they are not so effective when considering volumetric risk caused by adverse weather since correlation between energy price and weather is not 
as strong as the one between quantity and weather. This way, a risk that payoff of commodity futures may not be substantial to cover incurred financial loss is present. This standpoint can be confirmed by the findings of [19] who analyzed the movements of electricity price and temperature and found a correlation coefficient of about 0.5. Afterwards the relation between electricity consumption and temperature was analyzed and respective correlation coefficient was determined to be over 0.95. This is vivid evidence that weather is primarily a quantity risk and that it has an indirect affect on prices of commodities and services, through the effect on quantity of goods sold or produced.

The four mentioned risk management strategies [20] divided into active and passive in a way that passive include avoidance and acceptance, and active reduction and transfer.

Given the specificities of weather as a source of risk and the fact that all mentioned strategies of risk management possess certain disabilities when speaking of weather risk management, new management solution needed to be found. Since the financial impact of weather on energy and utility sector has been strong, it was economically sound to spend large sums of money in an effort to come up with a solution for reduction of uncertianty of future earnings [21]. In such circumstances, weather derivatives have emerged in 1997 and currently they provide the most effective protection against weather risk.

\section{WEATHER DERIVATIVES AS A RISK MANAGEMENT TOOL IN ENERGY SECTOR}

Weather derivatives are derivative instruments whose payoffs are based on a specified weather event and are used to hedge the financial impact of weather fluctuations. More detailed definition is given by [22] according to whom weather derivatives are defined as financial derivative instruments (futures, options, etc.) with synthetic weather index as underlying. The weather index is computed by quantifying the deviation of meteorological elements (temperature, rainfall, snowfall, wind speed, frost, etc.) and weather indices (CDD, HDD, etc.) from the selected reference level. The deviation is calculated based on observations of actual weather conditions in the specified climatologic stations. Then, to each degree of deviation a certain monetary value is given, and derivative contracts become valuable when the level of selected weather variable falls below or rises above the predetermined threshold, depending on the position taken. In this way, weather has been converted into a tradable good.

The momentum for creating weather derivatives were deregulation of the energy and utility industries in USA in mid-1990s [23] and extremely worm El Nino winter 1997/1998 in USA [24]. With deregulation, monopolies began to be replaced with competitive market structures and many energy and utility companies learned that while they could hedge away price risk with futures and options on energy itself, they had no instrument to hedge away weather risk that could dramatically alter the demand for or production of their products. It was in this environment that weather derivatives made public debut in 1997 with an over-the-counter transaction between Koch Industries Inc. and Enron Corp.

Reference [5] states that weather derivatives currently present the most effective instrument of protection against adverse weather because they (1) transfer the risk to the other party that is able to manage it more effectively (advantage over diversification), (2) provide compensation for losses incurred (advantage over the contract contingencies), (3) offer a payment based on index value and field inspection is not necessary in order to determine the loss (advantage over traditional insurance contracts), (4) do not require an insurable interest in the subject of insurance, therefore, allow for speculations that are important to maintain market liquidity (advantage over the index insurance contracts) and (5) since the weather risk is primarily the quantity risk, the possibility that the payoff under the weather futures contract is insufficient to cover the damage is minimized (advantage over commodity futures contracts).

Majority of weather derivatives are written on HDD index because energy companies constitute about half of weather derivatives users [25] and temperature proves to be more volatile in the winter [26]. It should be noted that, given the fact that company revenues are subjected to both price risk and quantity risk, weather derivatives are most effective when used in combination with commodity futures. Such hedging strategy is known as cross hedging.

\subsection{Application of weather derivatives by natural gas companies}

Next is presented a hypothetical example of how weather derivatives can be applied by natural gas distributor worried about warm winters. In order to arrange proper weather protection in the form of a derivative, gas distributor should define underlying weather index and time period during which his earnings are highly weather sensitive. Given that, accumulated weather index can be computed. Let us assume that distributor had analysed his historical sales and determined that November is most volatile i.e.risky winter month. He decides to write weather protection on HDD index for Novemeber. Next, reference level that serves as a trigger point for payout needs to be defined, i.e. strike point. Strike point is commonly calculated as historical average. Assume that historically in Novemeber, an HDD index value of 120 is accomplished. After conducting the quantitative weather sensitivity analysis, distributor became aware that 1 HDD point is worth 10,000 monetary units (m.u.) of natural gas sales. The monetary value attached to one index point is called tick. Given that HDD index measures deviation of winter temperatures beneath $18^{\circ} \mathrm{C}$ (equivalent to $65^{\circ} \mathrm{F}$ in Anglosaxon area), the higher the value of accumulated index the higher will be gas consumption. 


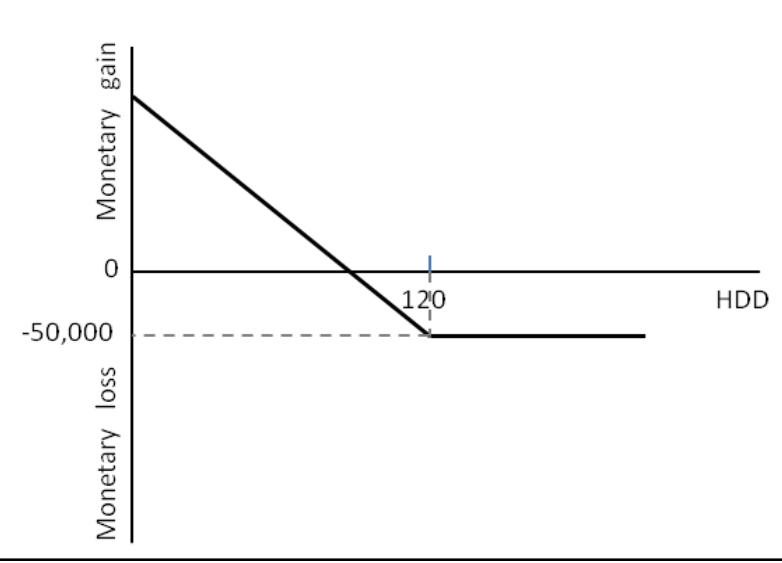

Fig. 3. Payout of a HDD put option

In other words, distributor is worried about fall of accumulated HDD index under 120 points, so he buys a weather protection in a form of a HDD put option 1 with strike of 120 HDDs and tick value of 10,000 m.u. For this protection, he pays an upfront premium of, let us assume, 50,000 m.u. Since weather is not a physical commodity, weather derivatives are always settled in cash. Equation (3) presents the payout formula for put option.

$$
\mathrm{P}_{\text {put }}=\text { tick } \times \max [(\mathrm{S}-\mathrm{W}), 0]-\text { premium }
$$

$\mathrm{S}$ is strike level and $\mathrm{W}$ is observed accumulated value of weather index during covered time period. Payout of a weather derivative is completely objective since it is contigent only on the value of accumulated weather index during the covered time period and no field inspection is required. Let us assume that during covered November a total of 100 HDDs was recorded - 20 HDDs under historical average consequently causing 200,000 m.u. lesser sales than predicted by average. In such circumastances, distributer would choose to excercise the option and would receive a net payment of 150,000 m.u. [10,000 x (120 HDD - 100 HDD $)-50,000]$. This payment would to some extent cover the loss of reduced sales of natural gas caused by mild winter. If the winter was cold, gas distributer would achieve higher sales of natural gas and would use these extra profits to cover the cost of the premium. Fig. 3. graphically presents payout of a considered HDD put option. Often, payouts by weather derivatives are limited to some maximum amount. Such analogy is consistent with their role as instruments of protection against non-catastrophic weather. Limited put option is called floor. The lower the maximum payout (limit), the lower is the option premium. Equation (4) presents the payout formula for floor option.

$$
\text { Pfloor }=\min [T \times \max \{(\mathrm{S}-\mathrm{W}), 0\}, \text { limit }]-\text { premium }
$$

The hedging effectiveness of weather derivatives for U.S. power producers was examined empirically. Using

\footnotetext{
${ }^{1}$ Option is a type of derivative contract that gives buyer the right, but not the obligation, to buy (for a call option) or sell (for a put option) a specific amount of a given stock, commodity, currency, index, or debt, at a specified price (the strike price) during a specified period of time. For such right buyer pays seller upfront a fixed amount of premium.
}

power load and temperature data [26] performed weather sensitivity analysis and on the basis of minimum variance criterion confirmed weather derivatives effectiveness. Reference [27] explored the feasibility of weather derivatives as a risk management tool employed by energy companies in order to protect consumers against extremely high gas bills during exceptionally cold winters. Such approach is quite different from conventional consideration of weather derivatives application in energy sector. Findings confirmed effectiveness of weather derivatives as a hedge against extreme gas bills. Based on the research findings important implication for practice can be found: by employing weather derivatives energy companies can, not only, hedge their revenues in the case of warm winter but can as well hedge the revenues of their consumers in the case of cold winter thus enhancing their satisfaction and loyalty. Of course, prerequisite for such application of weather derivatives is deregulation of energy sector.

\subsection{Application of weather derivatives by wind power plants}

When considering production of energy, nowadays major emphasis is put on renewable sources. In Croatia, production of electric energy from hydro power plants, wind power plants and other renewable sources is continuously growing. Next, a hypothetical example is given of how weather derivatives can be applied by a wind power plant as a hedge against unfavourable wind speeds i.e. low levels of CWSI. First a weather sensitivity analysis needs to be conducted in order to gain insight into time period that needs to be covered and to define monetary value of one CWSI point. Let us assume that management of a wind power plant wishes to insure against low wind speeds within whole year. The yearly expected value of CWSI is 2,500 points and the wind power plant has five wind turibines. After having analysed weather sensitivity, management knows that one CWSI point causes lesser annual energy production in amount of $7 \mathrm{MWh}$ per turbine, i.e. $35 \mathrm{MWh}$ per plant. If MWh is selling on average for 100 m.u., the monetary value of one index point is set to $3,500 \mathrm{~m}$.u. Unlike the natural gas distributor, wind power plant does not wish to pay an upfront premium for weather protection so it decides to sell a wind futures contract with strike level set to 2,500 CWSI points and tick value of 3,500 m.u. per index point. Equation (5) shows the payout formula for selling of weather futures.

$$
\mathrm{P}=\mathrm{T} \times(\mathrm{S}-\mathrm{W})
$$

$\mathrm{T}$ is tick value, $\mathrm{S}$ is strike level and $\mathrm{W}$ is registered value of weather index observed during covered period. Payout for a seller is positive only if accumulated value of weather index during covered period is below predefined strike, otherwise the seller is obliged to pay out a buyer. Entities wishing to hedge against high levels of weather indices would buy weather futures. Let us assume that in a hedged year a total of 2,430 CWSI points was registered $-70 \mathrm{CWSI}$ point below expected. In that case, a wind power plant receives a payout of 245,000 monetary units $[3,500 \mathrm{x}(2,500 \mathrm{CWSI}-2,430 \mathrm{CWSI})]$. 


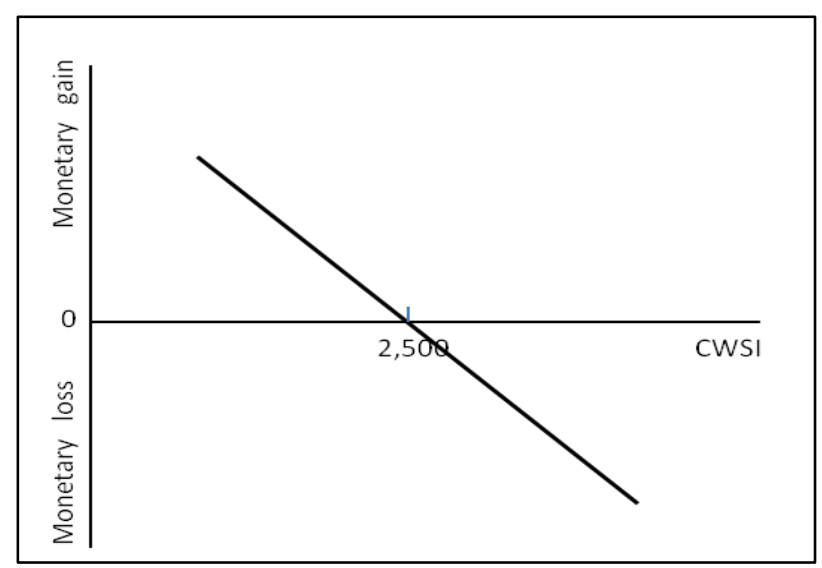

Fig. 4. Payout of selling a wind futures contract

Fig. 4. graphically presents the payout of selling CWSI weather futures. If more than 2,500 CWSI points were recorded during observed period, the wind power plant would be obliged to pay out the buyer of a futures contract. The underlying assumption is that the negative result on the futures market would be covered by the extra profits gained from the higher levels of CWSI and higher energy production.

\section{CONCLUSION}

Weather has long been blamed for poor business results and studies show that weather poses a significant source of quantity risk for every economic activity. In spite of that, many companies had completely avoided weather risk or were simply trying to cope with the consequences as good as they could - none of which provided them with adequate indemnity. However, the financial impact of weather on energy sector has been so strong it was economically sound to spend large sums of money in an effort to develop an effective solution for reduction of uncertianty of future earnings. In such circumstances, weather derivatives have emerged in 1997 and currently they provide the most effective protection against weather risk. Payoffs of weather derivatives are based on a value of objectively computed weather index and are used to hedge the financial impact of weather fluctuations. This way, weather was turned to commodity and trade of weather risk was enabled. Payouts of weather derivatives can be used to cover excess costs and/or reimburse lost sales caused by adverse weather. That way, application of weather derivatives can bring companies much needed stabilization of earnings which can consequently result in lower interests at which companies borrow capital. Weather derivatives show high potential for energy sector, especially when considering exploitation of renewable sources.

\section{REFERENCES}

[1] Auer, J. (2003) Weather derivatives heading for sunny times, Frankfurt Voice, Deutsche Bank Research, pp. 1-8

[2] Lazo, J.K., Lawson, M., Larsen, P.H., Waldman, D.M. (2011) U.S. economic sensitivity to weather variability, American Meteorological Society, June, pp. 709-720

[3] Subak, S. et al. (2000) The impact of the anomalous weather of 1995 on the U.K. economy, Climatic change, Vol. 44, pp. 1-26

[4] Weatherbill, Inc. (2008) Global sensitivity: a comparative study, str. 1-43. Available from: http://www.weatherbill.com/assets/
LandingPageDocs/Global-Weather-Sensitivity.pdf Accessed: 2012-03-14

[5] Stulec, I. (2010) Studying impact of weather on businesses in Republic of Croatia, Zbornik Ekonomskog fakulteta u Zagrebu, Vol. 8, No. 2, pp. 163-178. (original language: Croatian)

[6] Liu, X. (2006) Weather derivatives: a contemporary review and its application in China, Master Thesis, University of Nottingham

[7] Brockett, P. L., Wang, M., Yang, C. (2005) Weather derivatives and weather risk management, Risk Management and Insurance Review, Vol. 8, No. 1, pp. 127-139

[8] Edrich, C. (2003) Weather risk management, Journal of Financial Regulation and Compliance, Vol. 11, No. 2, pp. 164168

[9] Lehman, R.L., Warren, H.E. (1994) Projecting monthly natural gas sales for space heating using a monthly updated model and degree-days from monthly outlooks, Journal of Applied Meteorology, Vol. 33, pp. 96-106

[10] Li, X., Sailor, D.J. (1995) Electricity use sensitivity to climate and climate change, World Resou. Rev., Vol. 7, No. 3, pp. 334346

[11] Pardo, A., Meneu, V., Valor, E. (2002) Temperature and seasonality influences on Spanish electricity load, Energy Economics, Vol. 24, pp. 55-70

[12] Giannakopoulos, C., Psiloglou, B.E. (2006) Trends in energy load demand for Athens, Greece: weather and non-weather related factors, Climate Research, Vol. 31, pp. 97-18

[13] Guo,Z., Xiao,X. and Li, D. (2000) An assessment of ecosystem services: water flow regulation and hydroelectric power production, Ecological Applications, Vol. 10, No. 3, pp. 925-936

[14] Caporin, M., Pres, J. (n/a) Modelling and forecasting wind speed intensity for weather risk management, Computational Statistics and Data Analysis, in press

[15] Dorfman, M.S. (2007) Introduction to Risk Management and Insurance, Prentice Hall, Englewood Cliffs

[16] Myers, R. (2008) What every CFO needs to know about weather risk management, Chicago Mercantile Exchange \& Storm Exchange, Inc., pp. 1-23, Available from: http://www.wrma.org/documents/WeatherRisk_What_Every_CF O_Needs_to_Know_Now.pdf, Accessed: 2012-03-02

[17] Uran, V. (2006) The techniques of exercising futures and forwards by the hedging method, Energija, Vol. 55, No. 5, pp. 578-596

[18] Uran, V. (2007) The principle of exercising options on the electricity market, Energija, Vol. 56, No. 1, pp. 114-133

[19] Paoletti, C. (2001) Weather Derivatives; A Beginner`s Guide, The Oxford Princeton programme - Press Room [online], Available from: http://www.oxfordprinceton.com/press/ ar0103.asp, Accessed: 2011-02-16

[20] Lazibat, T., Zupanic, I. (2010.) Weather derivatives - an innovative product of futures market, Proceedings of $2^{\text {nd }}$ International Conference ,Vallis Aurea - focus on: Regional Development", ISBN 978-953-7744-06-9, ISBN 978-3-90150976-6, Editor Branko Katalinic, Published by Polytechnic of Pozega, Croatia \& DAAM International Vienna, Austria, pp. 0729-0735

[21] Tindall, J. (2006) Weather derivatives: pricing and risk management applications, Institute of Actuaries of Australia, pp. 1-13. Available from: http://www.actuaries.asn.au/library/events/ Conventions/2011/SecuritiseThis-Paper2.pdf, Accessed: 2012 04-10

[22] Lazibat, T., Zupanic, I., Bakovic, T. (2009) Weather derivatives as futures market instruments, Ekonomska misao i praksa, Vol. 18, No. 1, pp. 59-78. (original language: Croatian)

[23] Cao, M., Li, A., Wei, J. (2004) Watching the weather report, Canadian Investment Review, Vol. 17, No. 2, pp. 27-33

[24] Jones, T.L. (2007) Agricultural applications of weather derivatives, International Business \& Economics Research Journal, Vol. 6, No. 6, pp. 53-60

[25] WRMA/PwC survey presentation (June 2006) Available from: http://www.wrma.org/members_survey.html Accessed: 2012-0412

[26] Yang, C.C., Brockett, P.L., Wen, M.M. (2009) Basis risk and hedging efficiency of weather derivatives, The Journal of Risk Finance, Vol. 10, No. 5, pp. 517-536

[27] Leggio, K. B., Lien, D. (2002) Hedging gas bills with weather derivatives, Journal of Economics and Finance, Vol. 26, No. 1, pp. $88-100$ 